\title{
The Socio-economic Status of Horse Owners in Rural Areas of Bangladesh
}

\author{
M. P. Alam, M. S. A. Bhuiyan and A. K. F. H. Bhuiyan* \\ Department of Animal Breeding and Genetics, Faculty of Animal Husbandry, Bangladesh \\ Agricultural University, Mymensingh-2202, Bangladesh \\ *Corresponding author and Email: bhuiyanbau@gmail.com
}

Received: 18 February 2015

Accepted: 06 June 2015

\begin{abstract}
A study was conducted for a period of 60 days to understand the socio-economic status of the horse keepers and explore the opportunity of Indigenous horse rearing in 22 villages of Mymensingh, Tangail, Sherpur and Jamalpur districts in Bangladesh. A total of 200 horse keeping households were surveyed through one-to-one interview. A pre-tested questionnaire was used to collect information. Farmer exercised traditional knowledge on horse rearing that was used mainly for pulling cart, transportation, land tillage and sports purposes for their livelihood. Most of the horse keepers were experienced in horse rearing for 0.2 to 40 years. Among the horse keepers $54 \%$ were landless followed by marginal $(22.5 \%)$, small $(12.5 \%)$, medium $(8 \%)$ and large $(3 \%)$. Their main occupation was horse pulling cart $(88 \%)$ and the income from horse pulling cart was different from season to season which ranged from TK 3,000 to TK 20,000 per month. In case of secondary occupation, $81.5 \%$ farmers were involved in agriculture sector and $9 \%$ farmers involved in horse pulling cart. The horse keepers were mostly illiterate $(84.7 \%)$, where the highest education level was S.S.C (1\%). This study revealed valuable information which would help in designing proper policy and plan for the improvement of horse genetic resources and their keepers in Bangladesh.
\end{abstract}

Keywords: Indigenous horse keepers, socio-economic status

\section{Introduction}

Bangladesh is an agro-based country where livestock is playing an important role to uplift the socio-economic status of the rural farmers. Among livestock, horse called non-ruminant species is widely used for drought purposes such as pulling cart, transportation, land tillage and racing. It supports each family in densely populated pocket area since horse density area from ancient time. In the developing world, horses are the most important source of agricultural energy and transport for resourcepoor communities in both urban and rural areas (Biffa and Woldemeskel, 2006; Swann, 2006) and in Brazil, the use of horses directly employs more than 600 thousand people and involves around 3.1 billion dollars per year (Lima et al., 2006) constituting an important chain in the national agribusiness, strongly correlated with leisure, culture, sport and tourism (Guerra, 2003). But reluctantly, it is true that there is no actual data as to how much people are directly involved in horse occupation, extant of use and their economic contribution in Bangladesh. Though livelihood of many people in horse pocket areas depends on horse occupation still they have no scientific idea as to how to improve the horse production through good management system. Therefore, the present study was 
conducted to study the socio-economic status of horse keepers and to reveal the opportunity of horse rearing in rural areas of Bangladesh.

\section{Materials and Methods}

\subsection{Locale of the study}

The study was conducted in the four districts Mymensingh, Tangail, Sherpur and Jamalpur. Out of these four districts, 22 villages were selected purposively which were considered as horse pocket areas.

\subsection{Population and Sampling}

Among the horse keeping population in Mymensingh, Tangail, Sherpur and Jamalpur, a total of 200 households were randomly selected.

\subsection{Data collection and statistical analysis}

Before data collection, an interview schedule was prepared keeping in view the objectives of the study. Then it was pre-tested among the population who were not included in the sample. After necessary corrections and modifications the final questionnaire was prepared and multiplied. The observed socio-economic parameters were: land holding, level of education, experience in horse rearing, primary occupation, secondary occupation, monthly income, source of horse and income from horse pulling cart. Data were collected during 01 September to 30 October in 2014 through faceto-face interview with the respondent horse keepers.

The data generated from this experiment were entered in Microsoft Excel Worksheet, checked, organized and processed for further analyses. Frequency and percentage for different variable / traits were estimated with the help of Statistical Analysis System (SAS, 2003).

\section{Results and Discussion}

\subsection{Land holding}

Figure 1 shows that horses were reared mostly by landless people (54\%) followed by marginal $(22.5 \%)$, small $(12.5 \%)$, medium $(8 \%)$ and large (3\%) farmers. It was observed that in the study areas, horse pulling cart was the main source of earning for their livelihood in the society.

Approximately $98 \%$ horse in India contributes to the employment and income of the poor farmers and landless labors that primarily depend on livestock (www.nrce.gov.in). However, comparable information in the context of Bangladesh is unknown.

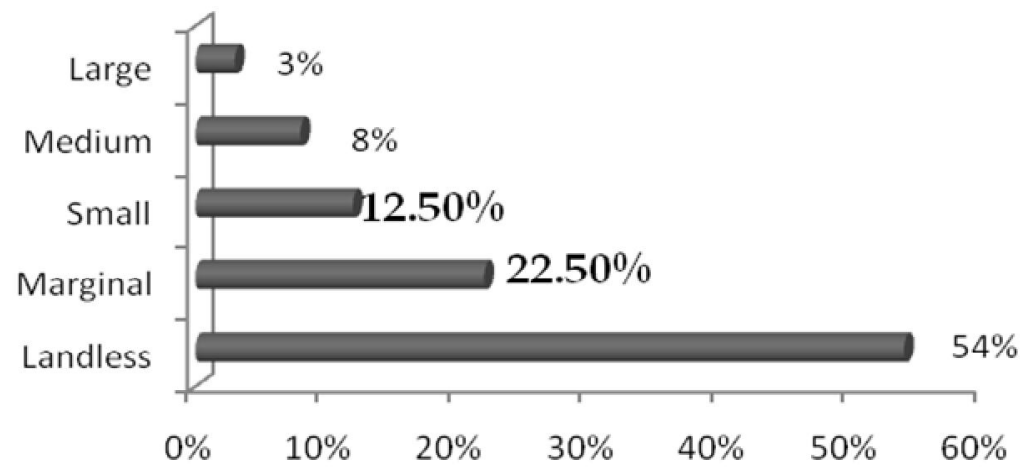

Figure 1. Land holding of the horse keepers 


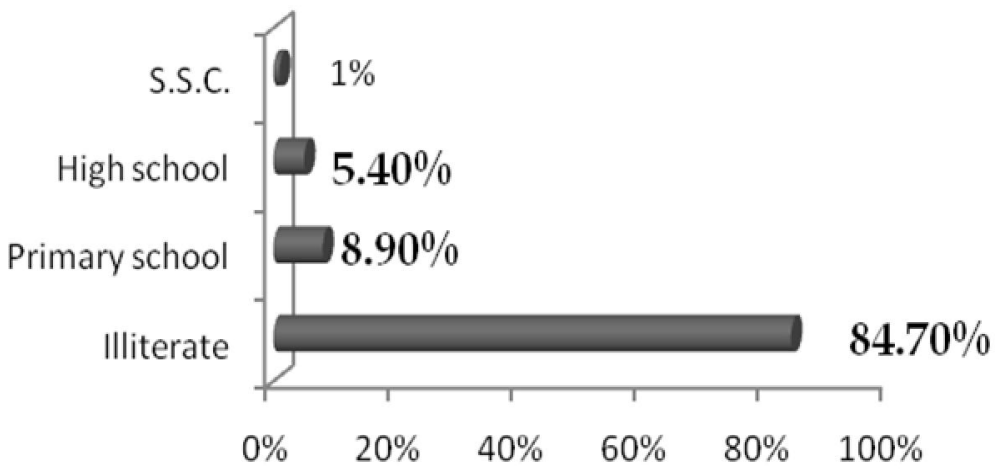

Figure 2. Literacy level of horse keepers

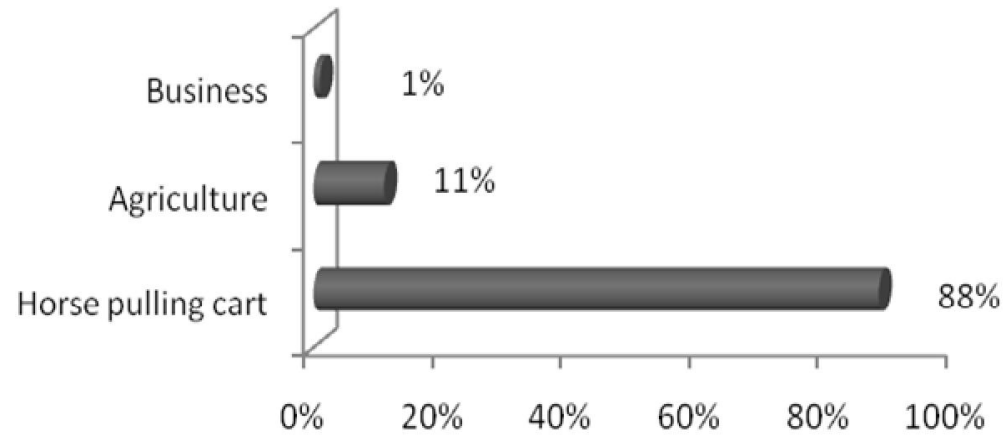

Figure 3a. Primary occupation of the horse keepers

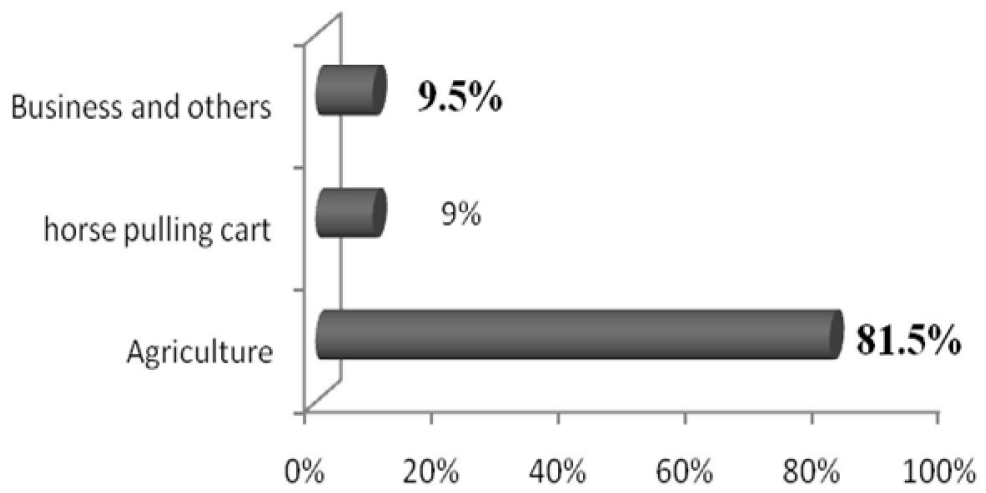

Figure 3b. Secondary occupation of horse keepers 


\subsection{Level of education}

The highest literacy level among the horse keepers was S.S.C (1\%) and most of the farmers were illiterate $(84.7 \%)$ who could sign their name only. Unconsciousness and low poverty line were the main reasons for their illiteracy. Among horse keepers most were from large families size that is why they faced many problems to run their families with proper food, dress, treatment and education etc. Detailed level of education of horse rearers are presented in Figure 2.

\subsection{Occupation}

\subsubsection{Primary occupation}

It was observed that in the study areas horse pulling cart was only and main source of earning for their livelihood in the society. Eighty eight percent of the horse keepers depended on their livelihood earned from horse pulling cart or transportation occupation, followed by $11 \%$ in agriculture and the remaining $1 \%$ in different business (Figure 3a). This occupation consequently has been continued from ancient time for some horse keeper's families and some new families newly involved in this occupation to run their family softly.

It becomes too difficult for the horse keepers to run their families if their horse or cart would face any problem. In developing nations, hundreds of millions of impoverished people depend on horse for their livelihood (Pritchard et al, 2005)and up to 20 persons could dependent on each animal for their daily survival (The Brooke, 2007).

\subsubsection{Secondary occupation}

In case of secondary occupation (Figure 3b), most horse keepers preferred agricultural work $(81.5 \%)$ and the rest of occupation were horse pulling cart (9\%), business and others $(9.5 \%)$.

\subsection{Income from horse rearing}

Figure 4 below portrays the sources of income from horse rearing. The highest income was TK 20,000 per month and the lowest was TK 3,000.
17.50, 37.50, 28.50 and $16.50 \%$ horse rearers earned a monthly amount of TK 3000-4000, 5000-6000, 7000-8000 and 9000-20000, respectively (Figure 4). Generally, the horse keepers used horse for pulling cart from 18 months and their foal were also used to kept with stallion/mare for known about pulling cart. Horse keepers earned more money in rice season (Chaitry-Boishakh) and fruit season (AsharSrabon) which ranged from TK 8000 to TK 20000 per months. In the rest of the season the horse keepers used to earn money TK 3000 to TK 6000 per month. The pick season and poor season income (with maximum and minimum) per day in four districts are presented in Table 1.There were district and seasonwise variations in income from horse rearing. The highest income per day in both peak and low season were estimated in Tangail region and the lowest were in Sherpur and Jamalpur districts.

On an average, the farmers used to get work for 20 days per month and the rest of the days, the horse were kept in the house. The highest or lowest income was found to depend on farmer's age. Generally, young and energetic farmers could earn more money than the old farmers. Horse pulling cart was used for loading and carrying soil, fruit, different vegetables, wood, sand, rice etc. . Every horse cart could load, on an average, 25 mounds in which farmers got TK 15 to TK 20 per mound.

Horse is a non-ruminant and undivided hoofed animal that's why its meat and milk are restricted or prohibited in the religion of Islam. Besides lack of knowledge, ignorance about its economic contribution, and ignorance of government, NGO, and research institutions are also responsible for no small or large horse farming in Bangladesh. One horse pulling cart can help a family easily that was observed in the study. In the study area horse was the only source of earning member on a day to day basis for their livelihood. If the horse fel in trouble, it was so difficult to run their family. 


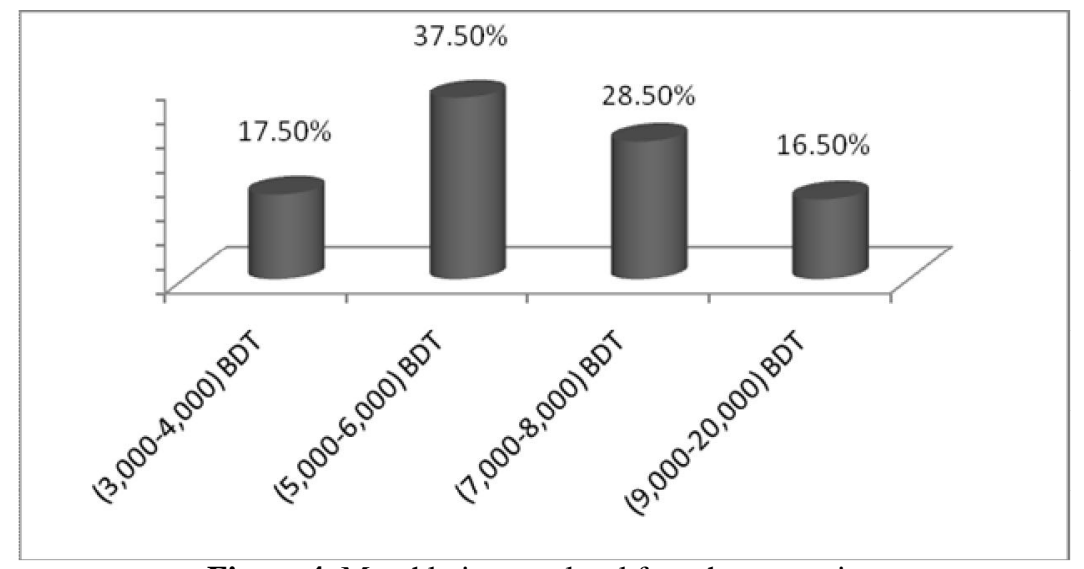

Figure 4. Monthly income level from horse rearing

Table 1. Income from horse rearing at peak and poor season

\begin{tabular}{|c|c|c|c|c|c|c|c|c|}
\hline \multirow[t]{2}{*}{ District } & \multicolumn{2}{|c|}{$\begin{array}{l}\text { Peak income } \\
\text { season/month } \\
\text { (Taka) }\end{array}$} & \multicolumn{2}{|c|}{$\begin{array}{c}\text { Peak income } \\
\text { season/day } \\
\text { (Taka) }\end{array}$} & \multicolumn{2}{|c|}{$\begin{array}{l}\text { Poor income } \\
\text { season/month } \\
\text { (Taka) }\end{array}$} & \multicolumn{2}{|c|}{$\begin{array}{l}\text { Poor income } \\
\text { season/day } \\
\text { (Taka) }\end{array}$} \\
\hline & Max. & Min. & Max. & Min. & Max. & Min. & Max. & Min \\
\hline Mymensingh & 15,000 & 8,000 & 1,000 & 5,00 & 5,000 & 3,000 & 5,00 & 3,00 \\
\hline Tangail & 20,000 & 10,000 & 15,00 & 1,000 & 7,000 & 4,000 & 5,00 & 4,00 \\
\hline Jamalpur & 12,000 & 8,000 & 1,000 & 5,00 & 6,000 & 3,000 & 6,00 & 4,00 \\
\hline Sherpur & 12,000 & 10,000 & 1,000 & 4,00 & 5,000 & 3,000 & 4,00 & 3,00 \\
\hline
\end{tabular}

Fazili et al. (2011) reported that in Kashmir, a horse is an important earning member of the poor family and for the poor owners of the horses, safe animal means safe family and safe family's means safe village. Income from horse pulling cart and transportation could contribute through share GDP in livestock sector. From the study area, it was estimated that the income of horse farmers was TK 3000 to TK 20000 per month. Horse sport is another important source of income that are arranged in different regions such as Sylhet, Rangpur, Mymensingh, Tangail, Sunamgonj, Natore, Bogra. If the government or private institutions take horse sports as a business in a large scale, then it has a chance to form large commercial horse farming in the country.
Recently in some regions like Rangpur and Sherpur, farmers used horses in agricultural purposes. Upon emphasis in horse farming, it is possible to largely use horse as drought animals to earn income. The horse manure may be used in agricultural land. Research suggest that working animal supply approximately $50 \%$ of agricultural power of total of the glob needs globally (Swann, 2006). Anonymous et al. (2003) reported that one adult horse produces about $10 \mathrm{t}$ of farm waste annually and Fazili et al. (2011) reported that the horse manure has been improving the agricultural and forest land of Kasmir and Jammu states.

Horse genetic resources in Bangladesh showed diverse phenotype and morphology and positive reproductive performance which indicate their potential for improvement (Alam, 2014). In Bangladesh, it has a good market demand at 
different areas. Most of the market side is own village or other villages. The biggest market place of horse selling is situated at Tulshipur Bazar in Jamalpur district. The price of an adult stallion or mare ranged from TK 30,000-80,000 and a colt or filly ranged from TK 5,000-30,000.

In rural areas, motor vehicle can be replaced by horse cart to minimize the fuel cost and environment pollution which is very important for future. The recent world wide surge in fuel prices has hit impoverished people, especially hard and consequently, in many developing countries, notably Pakistan and India, rising fuel prices are causing significant numbers of urban workers to switch from motorized vehicle to equine power carts (The Brooke, 2007). In rapidly industrialized countries such as Brazil, China, Ecuador, Egypt, India, Mexico, Morocco and Pakistan, donkey population remain stable and are predicted to continue to do so as long as there are significant rural populations without access to motor transport (Fernando and Starkey, 2004; Starkey and Starkey, 2004).

From the study areas it was found that there were a lot of constraints that suppressed the prospects of horse rearing in rural areas. Horses require more feed daily because of 7-8 hours daily hard working as a pulling cart. But it is true that for the rural people, it is difficult to meet up their demands for feed. As a result, horses in Bangladesh are suffering from malnutrition and reduce their productive and reproductive performances. Fazili et al. (2011) reported that poor body conformation and nutritional status, use of improper cart and saddles, playing on hard surface and over loading results in low work output and reduced life of the horse. Again Yousef et al. (1991) reported that horses are efficient uses of low quality, high fiber food, and can tolerate up to $20 \%$ dehydration.

Moreover, high mortality of foal was another constraint. The main reason for this mortality is pulling cart during pregnancy in addition with lack of consciousness or knowledge among horse keepers. The horse keepers have no knowledge about vaccination even there is no concern about its importance at government level. There was no vaccination program in the rural areas and horse faces different kind of unknown diseases. In rural condition, there is no opportunity for diagnosis of diseases due to lack of laboratory. As a result, they do not know the causes of diseases and preventive measure. Another major problem was the lack of veterinary services in the rural areas and the horse keepers relied on quack doctor or traditional treatment. Quack doctor treated the horse in rural areas at high fee or commission. Most of the people who rear horse are not aware about scientific methods of horse rearing. But in survey it was focused that they are interested to get training about horse rearing and management. The facilities regarding veterinary and extensive service are not efficient. However, lack of breeding knowledge, technique, and poor management were noticed (Alam, 2014).

\section{Conclusions}

From the findings it has become clear that there is a great opportunity to share GDP in livestock sector through horse farming in rural areas of Bangladesh. So, the government, national and international NGOs and private companies and research institutes should come forward for conservation and development of horse genetic resources and for improvement of the socioeconomic status of horse keepers of the country.

\section{References}

Alam, M. P. 2014. Phenotypic Characterization of Available Horse Resources of Bangladesh. MS thesis, Department of Animal Breeding \& Genetics, Bangladesh Agricultural University, Mymensingh, 54-56 pp.

Anonymous, 2003. National Research Center on equines, Hissar, India.

Biffa, D. and Woldemeskel, M. 2006. Causes and Factors Associated With Occurrence of External Injuries in Working Equines 
in Ethiopia. International Journal of Applied Research in Veterinary Medicine, 4: 1-7.

Fazili, M. R., Kirmani, M. A. 2011. The ignored working animal of Kashmir: status, constraints, research areas and ways for improvement. Asian journal of Animal Sciences, 5(2): 91-101.

Fernando, P. and Starkey, P. 2004. Donkeys and Development: Socio-Economic Aspects of Donkey Use in Africa, in: Fielding D. and Starkey P. (Eds). Donkeys, People and Development. A resource book in the Animal Traction Network for Eastern and Southern Africa (ATNESA). ACP-EU Technical Centre for Agricultural and Rural Cooperation (CTA).

Guerra, P., 2003. Riqueza eqüina do Brasil. In: Folha de São Paulo. Outubro de 2003.

Lima, R. A. S., Shirota, R. and Barros, G. S. C. 2006. Estudo do complexo do agronegócio do cavalo. CPEA/ESALQ/USP, Relatório Final, Piracicaba, SP, 251 p.
National Research Centre on Equines, Hisar, India/ www.nrce.gov.in.

Pritchard, J. C. 2005. Assessment of the Welfare of Working Horses, Mules and Donkeys, using Health and Behaviour Parameters. Prev. Vet. Med., 69: 265-83.

SAS Institute Inc. 2003. SAS/STAT User's Guide: Version 9.3.1., SAS Institute Inc., Cary,North Carolina, USA.

Swann, W. J. 2006. Improving the Welfare of Working Equine Animals in Developing Countries. Applied Animal Behaviour Science, 100: 148-151 pp.

The Brooke. 2007. Bearing a Heavy Burden. Available online at http://www.fao.org/fileadmin/user_upload /animalwelfare/Brooke eport.pdf (Accessed 02/ 08/ 2009).

Yousef, M. K., Fielding, O. and Pearson, R. A. 1991. Physiological responses of the heat stress in donkeys, mules and horses in tropical agricultural development, CTVM, Edinburgh, 96 pp. 